\title{
Investment confidence, corporate debt and income fluctuations*
}

\author{
D. Delli Gatti
}

Universitá Cattolica, 20123 Milano, Italy

\author{
M. Gallegati and L. Gardini \\ Universitá di Urbino, 61029 Urbino (PS), Italy \\ Received July 1990, final version received April 1992
}

In this paper we present a macroeconomic model with New Keynesian features which endogenously generates dynamic paths of income and the stock of corporate debt of a cyclic and chaotic nature. From the market clearing condition on goods and money markets we derive the dynamic paths of income and corporate debt whose stability properties depend upon the propensity to invest out of the flow of internally generated funds, which in turn is a positive function of income. If it is relatively 'low', the dynamic paths on income and corporate debt converge to their steady-state long-run values. When the propensity to invest is neither too "low' nor too 'high', the system can exhibit either bounded cycles or chaotic dynamics. Finally, if it exceeds a critical upper value, an explosive growth of debt occurs and a financial crisis is likely to ensue

\section{Introduction}

The real Business Cycle (RBC) hypothesis [Long and Plosser (1983)], explains business fluctuations as optimal responses of a macroeconomic system in Walrasian cquilibrium to random shocks of a technological nature. It is based on the Frisch-Slutsky view according to which fluctuations are caused by exogenous shocks imposed upon an inherently stable economic system.

In a series of recent papers [Day and Shafer (1985, 1987), Day (1989), Day and Lin (1991)], Hansen-Samuelson (endogenous) approach to business cycle

Correspondence to: Prof. Laura Gardini, Istituto di Scienze Economiche, Universitá di Urbino, Piazza della Repubblica 3, 61029 Urbino (PS), Italy.

${ }^{*}$ We are indebted to M. Amendola, W. Brock, R. Day, H. Minsky, J. Stiglitz and an anonymous Referee for their many stimulating comments and criticisms. Financial support from the Italian Ministry of Scientific Research (MURST) is gratefully acknowledged. This paper stems from the MURST Research Project on 'Nonlinear Economic Models and Complex Dynamics'. Domenico Delli Gatti wrote sections 1 and 2, Mauro Gallegati sections 3 and 5, Laura Gardini section 4. 
theory has been reconsidered in a Keynesian framework which, unlike the linear multiplier-accelerator interaction, generates 'irregular' dynamics that mimic the apparently random fluctuations of the main macrovariables.

The so-called New Keynesian (NK) Economics, on the other hand, has explored the macroeconomic implications of imperfections in the capital markets. ${ }^{1}$ In this paper we bridge the gap between these two lines of work by developing a non-linear dynamic model whose structure incorporates the basic ideas of the NK literature but retains the wage stickiness assumption of the Keynesian theory.

Following Stiglitz and Weiss (1981) we assume that information on the quality of borrowers is unevenly distributed among credit market participants. In contrast to the Modigliani-Miller theorem, this implies that the corporated capital structure is not irrelevant in investment decisions. Due to the presence of moral hazard and adverse selection on capital markets, a financing hierarchy or 'pecking order' can be devised in which internal finance ranks first, followed by bank loans and the issue of new equities.

The volume and direction of investment activity therefore depends on the financing constraints. Investment and debt accumulation, in turn, are ultimately responsible for the built-in dynamics of the model. We emphasize the key-role played by corporate cash flows in investment decisions. The 'propensity to invest', which captures the link between investment and cash flow, can be either smaller or greater than the propensity to save. In the former case the system is in a 'wary' regime, while the latter case can be characterized as an 'euphoric' regime.

As far as the money market is concerned, two distinctive features are worth mentioning. First of all, the need for external finance on the part of the business sector is incorporated in the demand for money. Moreover, the amount of liquidity generated by the banking system is demand-led, given the interest rate. In other words, the banking system accommodates the demand for bank loans (if credit rationing or a credit crunch do not occur) and therefore the supply of money is endogenously determined.

Market clearing on the goods and credit markets (but not on the labour market) yields the dynamic paths of income and corporate debt whose stability properties crucially depend upon the propensity to invest, which in turn is a positive function of income. If it is relatively 'low', the dynamic paths of income and corporate debt converge to their steady-state long-run values. When the propensity to invest is neither too low nor too 'high', the system can exhibit either bounded cycles or chaotic dynamics. Finally, if it

\footnotetext{
${ }^{1}$ The NK literature has been most recently surveyed by Gordon (1990) and Blanchard (1990). The NK research program is sketched by Stiglitz (1987). Sympathetic accounts of the NK approach can be found in Ball, Mankiw and Komer (1988) and Kotemberg (1987). 1 he most important papers in this line of research have been collected by Mankiw and Romer (1991).
} 
exceeds a critical upper value, an explosive growth of debt occurs and a financial crisis is likely to ensue.

Stochastic disturbances increase the irregularity of business fluctuations but don't alter their fundamental properties. However, a disturbance in the neighborhood of the critical values of the propensity to invest can induce time paths of a different nature (from chaos to a financial crisis, for instance).

Section 2 is devoted to a brief qualitative description of business fluctuations. In section 3 we present the building blocks of the model. The complex dynamic paths of income and corporate debt which stem from the non-linear market-clearing conditions are presented and discussed in section 4 . In section 5 we draw some conclusions.

\section{Analysis of the business cycle}

Before getting into details the main results can be presented without the technicalities. In the model, income and corporate debt follow endogenous dynamic paths whose fundamental propertics depend upon the propensity to invest (the partial derivative of the investment function with respect to income) which, in turn, depends upon the level of income, and therefore it changes over the business cycle.

On the income-debt plane, the system follows a counterclockwise motion along an asymmetric orbit. On average the ascending phase of business fluctuations lasts longer than the descending one. When the propensity to invest is relatively 'low', the steady-stage is locally stable, that is the dynamic paths of income and debt converge to their steady-state long-run values. When the propensity reaches a critical value the system switches to a regime of bounded cycles and chaotic dynamics. Finally, when investment activity overreacts to the flow of internal finance, an explosive growth of debt occurs and a financial crisis ensues.

In the following, we will focus on the nature of business fluctuations when bounded cycles and deterministic chaos occur. Suppose that the system is in a 'wary' state, that is the propensity to invest is lower than the propensity to save. In other words, a change in income has a greater impact on saving than on investment. During a phase of growing investment, income and profits increase through the working of the Keynesian multiplier. The growth of income implies a rise in retained profits which stimulates investment. Since the propensity to invest is smaller than the propensity to save, retained earnings and households' savings increase more than investment expenditures, thus reducing the need for external finance. As a consequence, the burden of debt commitments becomes lighter. As far as the demand for money is concerned, the positive impact of the increase in income on the demand for transaction balances is offset by the negative impact of the increase of profits on the demand for finance. If the impact of the increased 
demand for transaction balances prevails over the effect of the reduced demand for finance, the price of capital assets will fall exerting a depressing influence on investment. The opposite is true of course, if the latter effect prevails over the former.

This scenario describes a virtuous cycle in which the growth of investment, income, and cash flow is paralleled by the decline in the stock of debt. Inasmuch as the increasing cash flow stimulates investment, a transition to an 'euphoric' state occurs. In other words, the increase of income eventually makes the propensity to invest higher than the propensity to save. This configuration of parameters characterizes an 'euphoric' regime.

In such a state, income feeds upon investment in a spiralling boom of profits and capital accumulation, while the demand for external finance goes up, increasing debt commitments. When the flow of retained earnings does not catch up with the growing burden of debt commitments, a turning point in the business cycle will occur. During the downswing a change in entrepreneurial state of confidence is likely to happen. The decline of income would bring about a greater decrease in retained earnings with respect to the decline in investment and therefore cause an increase in the demand for external finance. In other words, by adopting a more cautious investment strategy in order to reduce indebtedness entrepreneurs would worsen the financial situation of their firms. This scenario describes a situation of debtdepression. Only when declining investment expenditure falls short of declining internal funds is the lower turning point of the cycle reached.

A financial crisis is likely to occur if the propensity to invest exceeds a critical ceiling. In such a case, the growth of debt commitments is so fast that the system experiences financial distress with widespread falls in income, investment and employment.

\section{The model}

Consider a closed economy consisting of households, firms and banks. Households supply labour and demand consumption goods, equities and money (deposits) for transaction and speculative purposes. Firms supply final goods and demand labour, investment goods and finance. Banks supply liabilities in the form of deposits, and demand assets in the form of loans. The central bank supplies bank reserves, the only type of high powered money in the model. We assume that firms are equity rationed: they do not raise risk capital by issuing new equities in order to avoid negative changes in the market evaluation of their capital stock [Myers and Majluf (1984)].

There are four markets: goods, labour, money and equities. As usual in Keynesian macromodels, we assume sticky prices and wages. As a consequence, up to the full employment frontier, excees supply always prevails. The price-rigidity assumption can be grounded in the NK literature on menu 
Table 1

Financial structure.

\begin{tabular}{|c|c|c|c|c|c|}
\hline \multicolumn{2}{|c|}{ Households } & \multicolumn{2}{|l|}{ Firms } & \multicolumn{2}{|l|}{ Banks } \\
\hline Assets & Liabilities & Assets & Liabilities & Assets & Liabilities \\
\hline $\begin{array}{l}H v \\
M\end{array}$ & $W$ & $p_{k} K$ & $\begin{array}{l}D \\
H v\end{array}$ & $\begin{array}{l}B \\
D\end{array}$ & $M$ \\
\hline
\end{tabular}

costs [Mankiw (1985)] or near rationality [Akerlof and Yellen (1985)]. Wage-rigidity can be linked to a reservation wage, which plays the role of a benchmark for the nominal wage rate.

The financial structure of the economy is summarized in table 1 . In a short run model we can ignore, for the sake of simplicity, technical progress and capital depreciation.

\subsection{The demand for goods and labour}

The core of the real side of the model is the investment function:

$$
I_{t}=a v_{t}+b I F_{t}, \quad a>0, b>0,
$$

where $I$ is investment, $v$ is the Stock price, $I F$ is internal finance. This is a strictly short run formulation of the investment function. In order to focus on the role of financial factors in business fluctuations, we do not take into account the contribution of investment expenditure to capital accumulation and the increase of productive capacity.

The first component in eq. (1) incorporates Tobin's ' $q$ ' theory of investment decisions. Given the price of current output, changes in the price of capital assets are equivalent to changes in the relative price of the 'representative machine' in use with respect to the newly produced machine. It captures the opportunity-cost of investing (purchasing new capital goods) with respect to taking over existing firms (purchasing capital goods in use).

The second component in eq. (1) is proportional to internal finance, defined as retained profits (lagged one period) net of debt service:

$$
I F_{t}=\theta \eta Y_{t-1}-r D_{t}
$$

where $r$ is the interest rate $(0<r<1)$ and $D$ is the stock of corporate debt. Due to asymmetric information on capital markets, internal finance ranks first in the financing hierarchy devised in section 1 [see Fazzari et al. (1988)]. Moreover, it records the past performance of the firm and is a key variable in easing the access to the credit market: from this point of view it is a proxy 
of collateral. The parameter $b$, which will be referred to hereafter as the propensity to invest (out of internal finance), plays a crucial role in determining the volume and direction of investment activity. In Keynes' terminology, it incorporates both the borrower's and the lender's risk [Keynes (1936)]. ${ }^{2}$

The propensity to invest is procyclical [as assumed in Minsky's financial instability hypothesis, see e.g. Minsky (1986)] due to a 'composition effect' argument which runs as follows. Following Fazzari et al. (1988), let's distinguish small-payout firms, which will be indexed by ' $s$ ', from high-payout firms (indexed by ' $h$ '). $S$-firms are characterized by a small capital stock, a high real sales and capital growth rate, a high retention ratio and a high propensity to invest out of their cash flow. This picture is clearly consistent with relatively young firms which have financial needs in excess of their cash flows and pay low dividends in order to retain all the low-cost internal funds they can generate. $H$-firms have a large capital stock, a low real sales and capital growth rate, a low retention ratio and a low propensity to invest out of their cash flow. They are relatively large and mature firms which do not face strictly binding financing constraints. ${ }^{3}$

The aggregate propensity to invest can be thought of as a weighted average of $s$-firms and $h$-firms propensities to invest ( $b_{s}$ and $b_{h}$ respectively), where the weights are represented by the ratio of the cash flow of each class to the total cash flow:

$$
b=b_{s} i f_{s}+b_{h} i f_{h}
$$

\footnotetext{
${ }^{2}$ Abel and Blanchard (1986) found that profits play an important role in aggregate $q$-type investment equations revealing the fact that alternative sources of finance are not perfect substitutes. Capitalizing on this conjecture, Fazzari et al. (1988) regress the rate of growth of the capital stock on Tobin's average $q$ and the ratio of internal cash flow to the stock of capital at replacement cost. Eq. (1) is analogous to Fazzari's reduced-form investment equation. In order to preserve consistency in our framework, however, the macro-variables which show up in eq. (1) are flows or levels, instead of rates of growth or ratios. A large body of literature, both theoretical and empirical, corroborates the 'financial view' of corporate investment. See, for instance, Calomiris and Hubbard (1988), Gertler and Hubbard (1988), Bernanke and Gertler (1989), (1990), Hubbard and Kashyap (1990). For instance, Bernanke and Getler (1989) develop a simple model of the business cycle in which business upturns increase corporate net worth and by lowering the agency costs of financing real capital investment stimulate capital accumulation.

${ }^{3}$ For example, according to data in Fazzari et al. (1988), $s$-firms, characterized by a dividendpayout ratio of less than 0.1 , on average, had a capital stock in 1984 of 320 millions of 1982 dollars, a real sales growth rate of $13.7 \%$ over the $1970-1984$ period, a retention ratio of $94 \%$ and a propensity to invest of 0.461 (computed by means of a reduced-form investment equation for $s$-firms over the $1970-1984$ period). $H$-firms, that is firms characterized by a dividend-payout ratio of more than 0.2 , had a capital stock of $2,190.6$ millions of dollars, a growth rate of $4.6 \%$, a retention ratio of $58 \%$ and a propensity to invest of 0.23 .

Data on $s$-firms reproduce Fazzari's descriptive statistics on his 'class 1' firms, while data on $h$-firms correspond to Fazzari's statistics on 'class 3' firms. Fazzari considers also an intermediate group (class 2) of firms characterized by a dividend-payout ratio ranging from 0.1 to 0.2 , which we have ignored in order to simplify the argument.
} 
$b_{s}$ and $b_{h}$ are given and known constants, whose relative magnitude is captured by the following inequality:

$$
\begin{aligned}
& b_{s}>b_{h} \\
& i f_{s}=I F_{s} / I F \text { and } I F=I F_{s}+I F_{h} . \text { Therefore } i f_{h}=I F_{h} / I F=1-i f_{s} . \text { As a } \\
& \quad \begin{array}{l}
\text { consequence: } \\
b=b_{s} i f_{s}+b_{h}\left(1-i f_{s}\right)=\left(b_{s}-b_{h}\right) i f_{s}+b_{h} .
\end{array}
\end{aligned}
$$

Therefore:

$$
\frac{d b}{d i f_{s}}=b_{s}-b_{h}>0
$$

that is, the aggregate propensity to invest positively depends on the share of the total cash flow generated by $s$-firms. Let $g_{s}$ and $g_{h}$ be the known and given cash flow growth rates of $s$-firms and $h$-firms, respectively. The aggregate cash flow growth rate is:

where

$$
g=g_{s} i f_{s}+g_{h}\left(1-i f_{s}\right)=\left(g_{s}-g_{h}\right) i f_{s}+g_{h},
$$

$$
g_{s}>g_{h}
$$

Therefore:

$$
\frac{d g}{d i f_{s}}=g_{s}-g_{h}>0
$$

that is, the aggregate cash flow growth rate positively depends on the share of the total cash flow generated by $s$-firms. We end up with:

$$
\frac{d b}{d g}=\frac{d b}{d i f_{s}} \frac{d i f_{s}}{d g}=\frac{b_{s}-b_{h}}{g_{s}-g_{h}}>0,
$$

that is, the aggregate propensity to invest is positively correlated to the rate of growth of the aggregate cash flow. If income is a reliable proxy of profits and cash flow, from the inequality above we can conclude that $b$ is procyclical. A business upturn is led by the fastest growing young smallpayout firms which rely primarily on the flow of internally generated funds in order to finance their investment. During the upswing the mature slowgrowing high-payout firms 'loose ground', so that their weight in the composition of total profits is reduced. On average, the propensity to invest out of internal finance goes up.

The propensity to invest therefore can be modeled as a positive function of the flow of (lagged) profits:

$$
b=\Phi\left(\eta Y_{t-1}\right) \text { or } b=f\left(Y_{t-1}\right) \text {. }
$$




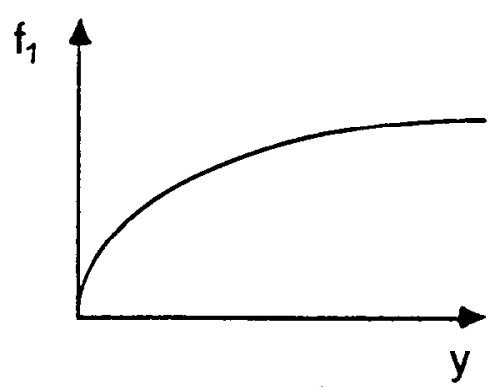

(a)

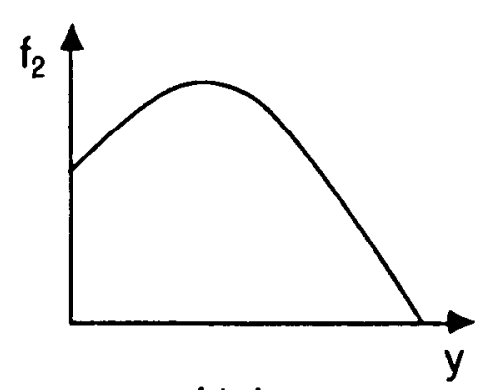

(b)

Fig. 1

We assume that $f$ is a generic positive function, continuously differentiable and bounded, in an appropriate range of values of $Y$. In particular, the following functional form for $f$ :

$$
f_{1}(Y)=b_{1} \operatorname{arctg}(Y) ; \quad b_{1}>0, Y>0,
$$

whose qualitative shape is illustrated in fig. 1a, will be used to discuss the dynamical behavior of the model. However, the bifurcation analysis of the model is carried out (in section 4) for the generic function $f$, thus other functional forms for $f$ work as well. In order to provide a second example, the following function (whose qualitative shape is illustrated in fig. 1b) has been used:

$$
f_{2}(Y)=b_{0}+b_{1} Y-b_{2} Y^{2} ; \quad b_{0}, b_{1}, b_{2}>0, Y \in\left(0, Y_{\max }\right) .
$$

Income $(Y)$ is defined by the following identities:

$$
\begin{aligned}
& Y_{t}=C_{t}+I_{t} \\
& Y_{t}=w N_{t}+\Pi_{t},
\end{aligned}
$$

where $C$ is consumption, $w$ is the nominal reservation wage, $N$ is employment and $\Pi$ is gross profits. All the macro-variables represent dated real magnitudes. We assume a linear technology:

$$
Y_{t}=\lambda N_{t},
$$

where $\lambda$ is average labour productivity. In order to simplify the argument, the stock of capital does not show up in the production function [eq. (8)]. This is no more than an analytical shortcut, which is consistent, however, 
with our short run theoretical framework. Firms follow a simple mark-up pricing rule:

$$
P=(1+\mu) \frac{w}{\lambda}
$$

where $\mu$ is the mark-up rate $(0<\mu<1)$. Letting the numeraire be the final good, we can assume: $P=1$. The share of profits in national income is:

$$
\eta=1-\frac{w}{\lambda}
$$

Following the empirical evidence shown by Hendry (1983), the demand for consumption goods is a function of current and lagged income:

$$
C_{t}=c_{0}+c_{1} Y_{t}+c_{1}^{\prime} Y_{t-1},
$$

where $c_{0}$ is autonomous consumption $\left(c_{0}>0\right), c_{1}$ and $c_{1}^{\prime}$ are the propensities to consume out of current and lagged income, respectively $\left(0<c_{1}<1\right.$, $0<c_{1}^{\prime}<1$ ).

Substituting eq. (10) into eq. (6) and taking into account eq. (8), we get the demand for labour:

$$
N_{t}=\frac{1}{\lambda\left(1-c_{1}\right)}\left[c_{0}+c_{1}^{\prime} \lambda N_{t-1}+I_{t}\right]
$$

where $1 / \lambda\left(1-c_{1}\right)$ can be conceived of as a sort of 'employment multiplier'.

Since investment is negatively related to the share of wages in national income eq. (11) can be thought of as a negatively sloped labour-demand schedule on the $(N, w)$ plane (see fig. 2). Assuming that the nominal wage rate is pinned down to the reservation wage, we can draw a horizontal labour supply curve, at least up to full employment $\left(N^{0}\right)$. Shifts of the labour demand functions, therefore, have only real effects.

The law of motion of debt is:

$$
D_{t}=D_{t-1}+F_{t},
$$

where $F$ is the amount borrowed. In equilibrium the need of external finance is equal to the flow-supply of funds on the part of the banking system, which in turn is proportional to the volume of internal finance:

$$
F_{t}=\beta I F_{t} ; \quad 0<\beta<1 .
$$

The volume of retained profits, in fact, is the most important criterion 


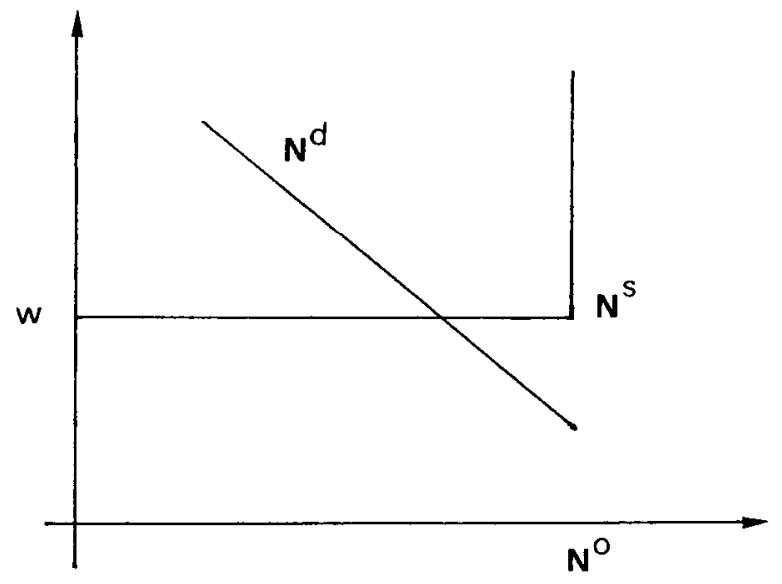

Fig. 2

followed by banks in screening investment projects [Calomiris and Hubbard (1988)].

Substituting eqs. (13) and (2) into eq. (12) we get:

$$
D_{t}=\frac{1}{\alpha}\left\{D_{t-1}+\beta \theta \eta Y_{t-1}\right\} ; \quad \alpha=1+r \beta,
$$

so that eq. (2) becomes:

$$
I F_{t}=\frac{1}{\alpha}\left\{\theta \eta Y_{t-1}-r D_{t-1}\right\},
$$

and eq. (1)

$$
I_{t}=a v_{t}+\frac{b}{\alpha}\left\{\theta \eta Y_{t-1}-r D_{t-1}\right\} ; \quad b=f\left(Y_{t-1}\right) .
$$

Substituting eqs. (10) and (1') into eq. (6) we get the following $I S$ equation:

$$
Y_{t}=\frac{1}{\left(1-c_{1}\right)}\left\{c_{0}+a v_{t}+c_{1}^{\prime} Y_{t-1}+\frac{1}{\alpha}\left(0 \eta Y_{t-1}-r D_{t-1}\right) f\left(Y_{t-1}\right)\right\}
$$

\subsection{Money market}

Equilibriun in the money market is brought about by the equality of the demand for money, $M_{t}^{d}$, and the supply of money, $M_{t}^{s}$. 


$$
M_{t}^{d}=M_{t}^{s}
$$

The rate of interest and the stock of high powered money $(B)$ are given. The supply of money is therefore determined by the current volume of debt [Tobin (1970), King (1983), King and Plosser (1984)]:

$$
M_{t}^{s}=B+D_{i} ; \quad B>0 .
$$

The demand for money can be distinguished in three components: 'active' balances, $T R$ (i.e. cash and demand deposits to be used in transactions), 'speculative' balances, SP (i.e. saving deposits to be held as assets in portfolios, together with cquitics), and 'finance', $F$ (i.e. money lent by banks to firms on a short term basis as part of long term financing schemes of investment projects):

$$
M_{t}^{d}=T R_{t}+S P_{t}+F_{t}^{d}
$$

The demand for transaction balances is a positive function of current income and the stock price:

$$
T R_{t}=k_{1} Y_{t}+k_{2} v_{t}
$$

where $k_{1}\left(0<k_{1}<1\right)$ is the reciprocal of the income-velocity of circulation. We assume $k_{2}>0$ because the transaction demand for money depends also on corporate net worth, which in turn is positively related to the stock price [Goldfeld (1976)]. Alternatively, following Hamburger (1977), we can link the opportunity cost of holding liquid balances to the dividend/price ratio. Once again, the demand for money is positively correlated to the price of capital assets.

The demand for speculative balances is a positive function of the expected capital loss. Given the expected price of capital assets, the demand for money as a store of value is a positive function of the current price of capital assets. This is basically the theory of the 'propensity to hoard' put forward by Keynes in the Treatise on Money. Taking into account the inverse relationship between the price and the rate of return of capital assets, however, this interpretation of the demand for speculative balances is not inconsistent with the theory of liquidity preference put forward by Keynes in the General Theory.

We define the demand for hoards of the $j$ th agent, $S P_{j}, j=1,2, \ldots, n$, as follows:

$$
\begin{aligned}
& S P_{j}=0 \quad \text { if } v<v_{j}, \\
& S P_{j}=a_{j}\left(v-v_{j}\right) \text { if } v \geqq v_{j},
\end{aligned}
$$


where $v_{j}$ is the (exogenous) future price of capital assets, and $a_{j}$ is a risk-aversion parameter for the $j$ th agent.

Whenever a capital gain is expected $\left(v<v_{j}\right)$ there is no incentive to hold liquid balances: the $j$ th portfolio consists only of equities. On the contrary, when a capital loss is expected, a (naive) portfolio diversification occurs: the individual demand for hoards increases linearly with the expected capital loss.

The aggregate demand for speculative balances is the sum of all the individual demands $\left(S P_{t}=\sum_{j} S P_{j}\right)$. If the individual expected prices are relatively close to each other, $S P_{t}$ can be approximated by a linear functional form:

$$
\begin{aligned}
& S P_{t}=0 \quad \text { if } \quad v<v^{e} \\
& S P_{t}=h\left(v-v^{e}\right) \quad \text { if } \quad v \geqq v^{e},
\end{aligned}
$$

where $h=\sum_{j} a_{j}$ is the sensitivity of the demand for hoards to the current stock price, and $v^{e}=\sum_{j} a_{j} v_{j} / \sum_{j} a_{j}$ is a weighted average of price exectations and will be referred to, hereafter, as the average expected price, or the 'average opinion' of investors with respect to the future asset price [sec Keynes (1936, ch. 11)].

In the following, we will assume that $v \geqq v^{e}$. In particular, we will deal with three different equations of the demand for speculative balances. When the stock market is not efficient, $v \geqq v^{e}$ and we can write:

$$
S P_{t}^{(1)}=h\left(v_{t}-v^{e}\right) \text {; exogenously given expectations. }
$$

Eq. (19) represents the speculative demand of type (1). When perfect foresight (realized expectations) occurs, that is when $v=v_{j}=v^{e}$, price expectations are uniform across agents (the individual and the average expected price coincide) and equal to the current market price. In this case, of course, no capital gain or loss is expected and as a consequence the speculative demand is zero:

$$
S P_{t}^{(2)}=0 \text {; realized expectations. }
$$

In a stochastic setting, we can conceive of a third form of speculative demand, modeled according to the rational expectations hypothesis, that is $v_{t}=v^{e}+\varepsilon_{v}$, where $\varepsilon_{v}$ is a random variable with a uniform distribution in a given range, say $R_{v}=\left[V_{\text {inf }}, V_{\text {sup }}\right], V_{\text {inf }}<0, V_{\text {sup }}>0$. Due to market disturbances the forecast error is independent of the predictions, so that the speculative demand boils down to:

$$
S P_{t}^{(3)}=\varepsilon_{v} ; \text { rational expectations. }
$$


In order to establish a unique formal respresentation of the three kinds of speculative demand described above, we can write:

$$
S P_{t}^{(i)}=h_{i} v_{t}+\delta_{i} ; \quad i=1,2,3
$$

where the case of

exogenously given expectations $S P_{t}^{(1)}$ is obtained with $h_{1}=h$ and $\delta_{1}=$ $-h v^{e}$

realized expectations $\quad S P_{t}^{(2)}$ is obtained with $h_{2}=0$ and $\delta_{2}=0$;

rational expectations $\quad S P_{t}^{(3)}$ is obtained with $h_{3}=0$ and $\delta_{3}=\varepsilon_{v}$.

The third component of the demand for money is the flow-demand for finance on the part of firms. Following Myers and Majluf (1984) and Greenwald, Stiglitz and Weiss (1984) we assume that firms are equity rationed. Therefore the demand for finance is

$$
F_{t}^{d}=I_{t}-I F_{t}=a v_{t}+(b-1)\left(\theta \eta Y_{t-1}-r D_{t}\right) ; b=f\left(Y_{t-1}\right) .
$$

The flow-supply of funds coming from the banking system, on the other hand, is positively correlated to the volume of the firms' internal finance [see eq. (13)]. Equilibrium on the 'market for finance' implies:

$$
F_{t}^{d}=F_{t}
$$

The money market stock-equilibrium condition (15), the finance market flow-equilibrium condition (24) and the law of motion of corporate debt (12) jointly considered imply:

$$
D_{t-1}+B=T R_{t}+S P_{t}^{(i)} ; \quad i=1,2,3 .
$$

Substituting eq. (18) into eq. (25), we get:

$$
Y_{t}=\frac{1}{k_{1}}\left(D_{t-1}+B-k_{2} v_{t}-S P_{t}^{(i)}\right)
$$

Eq. (26) is a peculiar $L M$ equation which incorporates both the money market stock-equilibrium condition and the finance market flow-equilibrium condition. Thanks to these conditions, the flow of finance which shows up both in the money demand and in the money supply equation can be compensated away.

\section{Nonlinear dynamics}

We shall first derive the dynamic model in the form of a nonlinear system 
of two difference equations, that is a two-dimensional map. From the $I S$ and $L M$ equations, which we rewrite for convenience of the reader:

$$
\begin{aligned}
& \left.Y_{t}=\frac{1}{\left(1-c_{1}\right)}\left\{c_{0}+a v_{t}+c_{1}^{\prime} Y_{t-1}+\frac{1}{\alpha}\left(\theta \eta Y_{t-1}-r D_{t-1}\right) f Y_{t-1}\right)\right\} \\
& Y_{t}=\frac{1}{k_{1}}\left(D_{t-1}+B-k_{2} v_{t}-S P_{t}^{(i)}\right)
\end{aligned}
$$

we obtain the explicit formulation of $v_{t}$ as a function of $\left(Y_{t-1}, D_{t-1}\right)$ :

$$
v_{t}=\frac{1}{\gamma}\left\{q-k_{1} c_{1}^{\prime} Y_{t-1}+\left(1-c_{1}\right) D_{t-1}-\frac{k_{1}}{\alpha}\left(\theta \eta Y_{t-1}-r D_{t-1}\right) f\left(Y_{t-1}\right)\right\},
$$

where

$$
\gamma=a k_{1}+\left(1-c_{1}\right)\left(k_{2}+h_{i}\right) ; \quad q=\left(1-c_{1}\right)\left(B-\delta_{i}\right)-k_{1} c_{0} .
$$

Substituting $v_{t}$ into eq. (26) we obtain the dynamic equation of $Y_{t}$ as a function of $\left(Y_{t-1}, D_{t-1}\right)$, which coupled with the equation for debt $\left(12^{\prime}\right)$ gives the system of two difference equations, say map $F,\left(Y_{t}, D_{t}\right)=F\left(Y_{t-1}, D_{t-1}\right)$, explicitly given by:

$$
(F)\left\{\begin{array}{l}
Y_{t}=\phi_{0}+\phi_{1} Y_{t-1}+\phi_{2} D_{t-1}+\phi_{e}\left(\theta \eta Y_{t-1}-r D_{t-1}\right) f\left(Y_{t-1}\right) \\
D_{t}=\frac{1}{\alpha}\left\{D_{t-1}+\beta \theta \eta Y_{t-1}\right\},
\end{array}\right.
$$

where

$$
\begin{aligned}
& \phi_{0}=\left[a\left(B-\delta_{i}\right)+c_{0}\left(k_{2}+h_{i}\right)\right] / \gamma>0 ; \phi_{1}=c_{1}^{\prime}\left(k_{2}+h_{i}\right) / \gamma>0 ; \\
& \phi_{2}=a / \gamma>0 ; \phi_{3}=\left(k_{2}+h_{i}\right) /(\alpha \gamma)>0 .
\end{aligned}
$$

The map $F$ yields interesting (complex) dynamics even if we assume perfect foresight or rational expectations. The analysis of the dynamic behavior of $F$ in the deterministic assumptions (speculative demand $S P_{t}^{(i)}$ with $i=1$ and $i=2$ ), will be the object of subsection 4.1 , and the results will be used in subsection 4.2 where we discuss the dynamics of the stochastic map $F$ (with speculative demand $S P_{t}^{(3)}$ ).

In the following we derive the conditions for the existence of a stationary point $E=\left(Y^{*}, D^{*}\right)$, and the sufficient conditions for the local asymptotic stability of $E$, pointing out that $E$ may become unstable via Hopf-bifurcation. By stationary point, we mean a fixed point of the map $F$ in the positive quadrant of the plane, i.e. $Y^{*}>0, D^{*}>0$, which is stable (under suitable conditions).

Assuming $b$ constant, the map $F$ reduces to a linear map, say $F^{1}$. It will be 
shown that the linear map $F^{1}$ has a positive equilibrium point which is of the focus type. Thus, the dynamic paths of the variables follow endogenous oscillations, which are of decreasing amplitude and convergent to the equilibrium point when the focus is stable; of increasing amplitude and divergent when it is unstable. It is in this second kind of regime that the effect of nonlinearity introduced by assuming $b=f\left(Y_{t-1}\right)$ becomes important. In fact, even if the (unique and positive) equilibrium point is unstable, the oscillating paths are not divergent but tend towards another stable attractor, which may be regular (a cyclic or periodic path), or something more complex, but with structure and bounds which may be analyzed.

\subsection{Deterministic chaos}

From eq. (28), if follows immediately that there exists a unique equilibrium point if and only if $r\left(1-\phi_{1}\right) \neq \theta \eta \phi_{2}$, in which case it is given explicitly by

$$
E=\left(Y^{*}, D^{*}\right)=\left(\frac{r \phi_{0}}{r\left(1-\phi_{1}\right)-\theta \eta \phi_{2}}, \frac{\theta \eta}{r} Y^{*}\right)
$$

Proposition 1. Let

(j) $r\left(1-\phi_{1}\right)>\theta \eta \phi_{2}$

(ji) $f\left(Y^{*}\right)<b^{h}, b^{h}=\frac{\beta \phi_{2}}{\alpha \phi_{3}}+\frac{\alpha-\phi_{1}}{\alpha \theta \eta \phi_{3}}$

then the (unique) equilibrium point $E$ is positive and stable.

Proof. From condition (j) it follows that $E$ is positive. To perform the local stability analysis of $E$, we denote by $J$ the jacobian matrix of $F$ evaluated at the equilibrium point, and by $\mathscr{P}(\lambda)$ its characteristic polynomial. We recall that sufficient conditions for the local asymptotic stability of $E$ are [Gandolfo (1983)]:

$$
\begin{aligned}
& \mathscr{P}(1)=\frac{\beta}{\alpha}\left[r\left(1-\phi_{1}\right)-\theta \eta \phi_{2}\right]>0 \\
& \mathscr{P}(-1)=2\left(\frac{1}{\alpha}+\phi_{1}\right)+2 \theta \eta \phi_{3} f\left(Y^{*}\right)+\frac{\beta}{\alpha}\left[r\left(1-\phi_{1}\right)-\theta \eta \phi_{2}\right]>0 \\
& \operatorname{det} J=\frac{\phi_{1}}{\alpha}+\theta \eta\left[\phi_{3} f\left(Y^{*}\right)-\frac{\beta}{\alpha} \phi_{2}\right]<1,
\end{aligned}
$$

where det stands for determinant. From the sign of the parameters of the 
map $F$ and assumption $(j)$ it follows that the first two conditions in (30) are satisfied, while the last condition in (30) follows from assumption (jj).

Some remarks are in order at this point, which can be throught of as corollaries of proposition 1:

- The equilibrium point $E$ is not economically meaningful when $r\left(1-\phi_{1}\right)<$ $\theta \eta \phi_{2}$, being $Y^{*}<0$. Moreover, in this case it follows, from the first expression in (30), that $\mathscr{P}(1)<0$. Thus, the equilibrium point is unstable (the eigenvalues of the jacobian matrix $J$ are real, and one of them is greater than 1). In this regime the model is not economically meaningful. Indeed, $E$ is the only fixed point and no other stable attractor has been numerically observed, whereas monotonically divergent orbits occur.

- The equilibrium point $E$ does not depend on $b$, i.e. on $f(Y)$, while it depends on the exogenous constants via the coefficient $\phi_{0}$. On the other hand, the local stability of $E$ does not depend on $\phi_{0}$, but depends on $f\left(Y^{*}\right)$.

- Under assumption ( $j$ ) the first two conditions in (30) are always satisfied, so that the stable equilibrium point $E$ cannot become a saddle point with an associated real eigenvalue greater than 1 , neither become unstable via flipbifurcation (through an eigenvalue equal to -1 ). But the equilibrium point $E$ may become an unstable focus via a Hopf-bifurcation, as it is shown in the following.

- Let $F^{1}$ denote the linear map obtained from $F$ when $b$ is constant. Then the equilibrium point $E$ of $F^{1}$ is globally asymptotically stable if and only if assumption $(j)$ holds and $b<b^{h}$. That is to say, $b^{h}$ is the bifurcation value of the linear model.

- If we perform the bifurcation analysis as a function of one of the parameters which define $f(Y)$, say $b_{1}$, then condition $(j j)$ can be rewritten in terms of $b_{1}$. For example, for the two functions $f_{1}$ and $f_{2}$ defined in the previous section we obtain:

$$
\begin{aligned}
& f_{1}\left(Y^{*}\right)<b^{h} \Leftrightarrow b_{1}<b^{1 h}=b^{h} / \operatorname{arctg}\left(Y^{*}\right) \\
& f_{2}\left(Y^{*}\right)<b^{h} \Leftrightarrow b_{1}<b^{2 h}=\frac{b^{h}-b_{0}}{Y^{*}}+b_{2} Y^{*}
\end{aligned}
$$

Proposition 2. Let

(j) $r\left(1-\phi_{1}\right)>0 \eta \phi_{2}$

(jjj) $\frac{d}{d b_{1}} f\left(Y^{*}\right) \neq 0$

then at $f\left(Y^{*}\right)=b^{h}$ the equilibrium point $E$ undergoes a Hopf-bifurcation.

Proof. When $(j)$ holds and $f\left(Y^{*}\right)-b^{h}$, the eigenvalues of $J$ are complex conjugates of modulus one: $|\lambda|^{2}=\operatorname{det} J=1$, and $d / d b_{1}|\lambda|=$ 
$1 / 2 \theta \eta \phi_{3} d / d b_{1} f\left(Y^{*}\right)$. Thus, under assumption (jjj) the transversality condition of Hopf's theorem for maps [Iooss (1979), Guckenheimer and Holmes (1983), Lorenz (1989)] is satisfied.

Corollary. Under assumption (j), $b^{1 h}$ and $b^{2 h}$, when $b=f_{1}(Y)$ and $b=f_{2}(Y)$ respectively, are Hopf-bifurcation values. In fact, $d / d b_{1} f_{1}\left(Y^{*}\right)=\operatorname{arctg}\left(Y^{*}\right)$, and $d / d b_{1} f_{2}\left(Y^{*}\right)=Y^{*}$.

We turn now to the dynamic behavior of the model when the equilibrium point is unstable. If the Hopf-bifurcation is supercritical then there exists an invariant attractive curve $\Gamma$, on which the orbits are generally quasiperiodic, that is, at least locally the trajectories are bounded and asymptotically cyclic. Moreover, as suggested by several examples of plane nonlinear maps [Gumowski and Mira (1980), Mira (1987), Gallegati and Gardini (1991)], the invariant curve $\Gamma$ may disappear on varying $b_{1}$ and other bounded attractors (periodic orbits, strange attractors or other attracting sets) may appear. We shall briefly discuss the numerical results obtained with the functions $f_{1}(Y)$ and $f_{2}(Y)$.

For several choices of the economic parameters we have found a supercritical Hopf-bifurcation of the equilibrium point $E$ at $b^{1 h}$ and $b^{1 h}$, and dynamic behavior similar to those of the examples reported in this paper. As the trajectories obtained with the realized expectations hypothesis $S P_{t}^{(2)}$ are similar in shape to those obtained with the speculative demand $S P_{t}^{(1)}$, in the figures we report only trajectories obtained with the exogenous expectations rule $S P_{t}^{(1)}$.

In the model with $b=f_{1}(Y)$, when $b_{1}>b^{1 h}, b_{1}$ near $b^{1 h}$, there exists an invariant attractive curve $\Gamma$ (fig. 3a). Increasing $b_{1}$, deformations of the shape of $\Gamma$ are followed by its disappearance. Stable cycles (or periodic orbits) appear, and a cycle undergoes a sequence of flip (or period-doubling) bifurcations, and annular (or ring-shaped) chaotic areas are observed around the repulsive point $E$. Inside these areas, of increasing width, a sort of 'cyclical aperiodic trend' in the trajectories is still maintained, although the dynamic is chaotic. The geometrical shape of a chaotic attractor is illustrated in fig. $3 b$.

The hole around the equilibrium point $E$ then shrinks to $E$, and the chaotic area becomes simply-connected. This bifurcation has been studied by Barugola, Cathala and Mira (1986), and in Gardini (1991) it is shown that the disappearance of the hole in the annular chaotic area coincides with the global bifurcation of $E$ from 'expansive' to 'snap-back repeller' [the definition and meaning of these terms can be found in Marotto (1978), Gabisch and Lorenz (1989), Lorenz (1989)]. Increasing further $b_{1}$, beyond a critical value, wc havc only detected numerically divergent trajectories. That is to say, the chaotic attractor has become unstable, the generic trajectory tends towards 

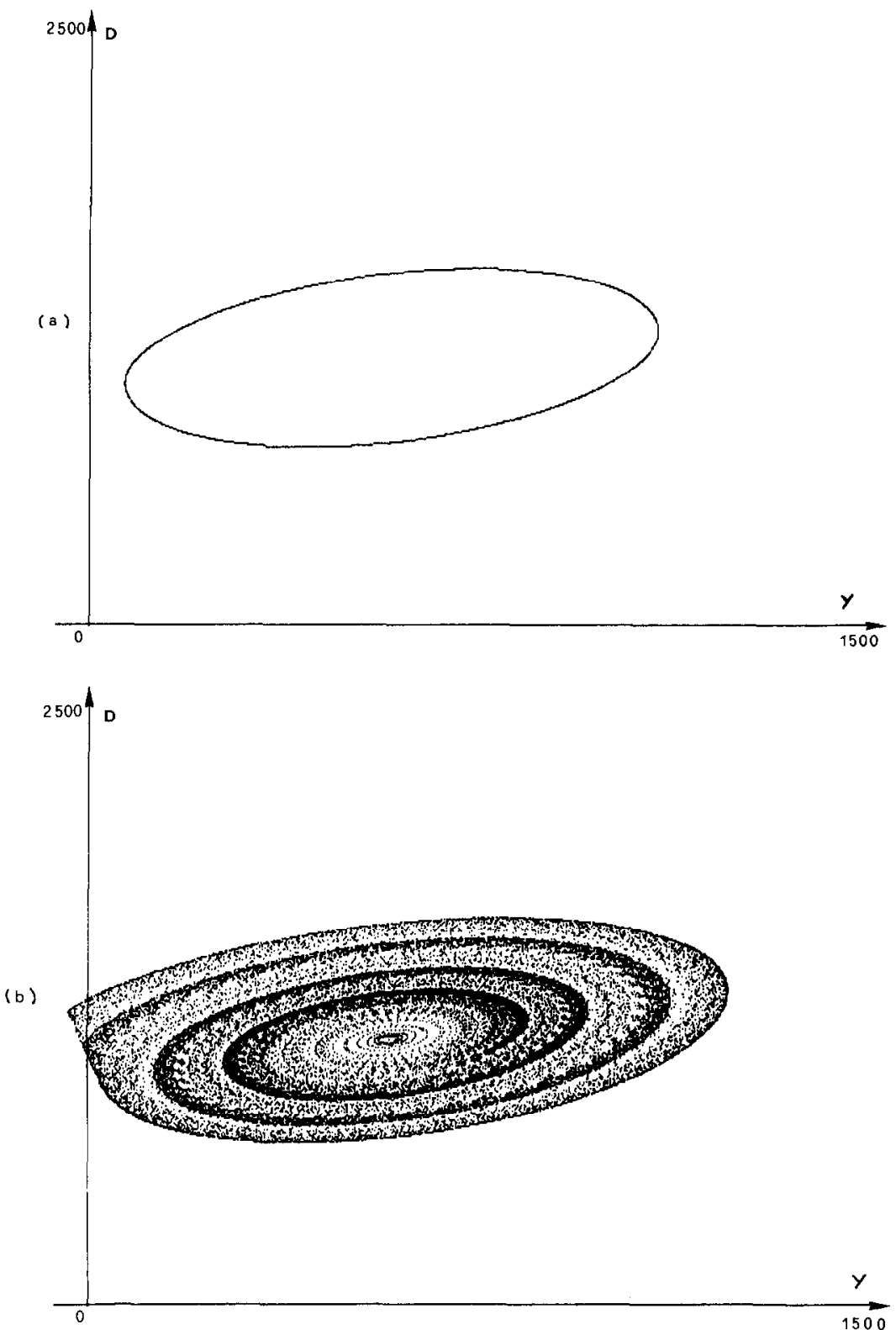

Fig. 3. Map $F$ with speculative demand $S P_{i}^{(1)}$ and $b=f_{1}(Y)$. The values of the parameters are as follows:

$a=0.1, \theta=0.5, \omega / \lambda=0.7, \beta=0.8, r=0.08, B=100, k_{1}=0.7, k_{2}=0.4, C_{0}=100, c_{1}=0.5, c_{1}^{\prime}=0.2$, $h=0.8, v^{e}=100$. The Hopf-bifurcation value is $b^{1 h} \simeq 1.7168 . b_{1}=1.72$ in (a); $b_{1}=1.76$ in (b). 
infinity, although a 'strange-repeller' (made up of infinitely many repulsive cycles) survive [Mira (1987)]. In the example reported in fig. 3 this global bifurcation which destroys the (chaotic) attractor occurs (at $b_{1} \simeq 2.5$ ) when the repulsive focus $E$ becomes a repulsive node [Gardini (1991)]. We have observed similar behaviors also with the function $b=f_{2}(Y)$ : when $b_{1}>b^{2 h}$ bounded orbits on invariant curves (fig. 4a) and strange attractors (fig. 4b) can be found.

Summing up, we can say that for a wide range of values of the parameters there exists a stable attracting set, say $\mathscr{A}$, of the map $F$, which may be an equilibrium point $(\mathscr{A}=E)$, a closed invariant curve $(\mathscr{A}=\Gamma)$, a chaotic area, say $S(\mathscr{A}=S)$ or a different set of points. A more difficult problem is to determine the basin of attraction of $\mathscr{A}$. We recall that, introducing the vector notation for points of the plane $X=(Y, D)$, so that the forward trajectory from a point $X$ is given by $X_{k}=F^{k}(X), k=1,2, \ldots$, the basin of attraction of $\mathscr{A}$ is the set of points $X$ whose forward trajectory $X_{k}$ tends to $\mathscr{A}$. However, it is often sufficient to determine a set $\Omega$ in the region of interest, that is mapped into itself under application of $F$, i.e.:

$$
F(\Omega)=\{F(X), X \in \Omega\} \subseteq \Omega .
$$

In such a case, if $\mathscr{A}$ is the only attractor in $\Omega$ then the generic point of $\Omega$ has a trajectory which tends towards $\mathscr{A}$. We illustrate a procedure to determine a region $\Omega$, mapped into itself under $F$. Starting from a chosen set $\Omega_{0}$, such that $\mathscr{A} \subset \Omega_{0}$, we consider its images: $\Omega_{k}=F\left(\Omega_{k-1}\right)=F^{k}\left(\Omega_{0}\right), k=1,2, \ldots$ In the simplest cases, there exists an integer $p$ such that

$$
\Omega=\bigcup_{k=0}^{p} \Omega_{k} \text { satisfies } F(\Omega) \subseteq \Omega \text {. }
$$

Moreover, the basin of attraction of $\Omega$, say $\mathscr{B}$, can be constructed in terms of its preimages:

$$
\mathscr{B}=\bigcup_{k=0}^{\infty} F^{-k}(\Omega) .
$$

As an example, we illustrate the numerical application of this procedure to determine such a set $\Omega$, whose trajectories are convergent to the attractors reported in fig. 3. The starting set $\Omega_{0}$ and the final set $\Omega=\bigcup_{k=0}^{15} \Omega_{k}$ are reported in fig. 5a and fig. 5b respectively. The attractor of fig. $3 a$ is also shown, as a comparison, and the same set $\Omega$ works well also for the attractor of fig. $3 b$.

To conclude this section, we need to point out that the rough procedure outlined above can be replaced by a rigorous method, which determines 

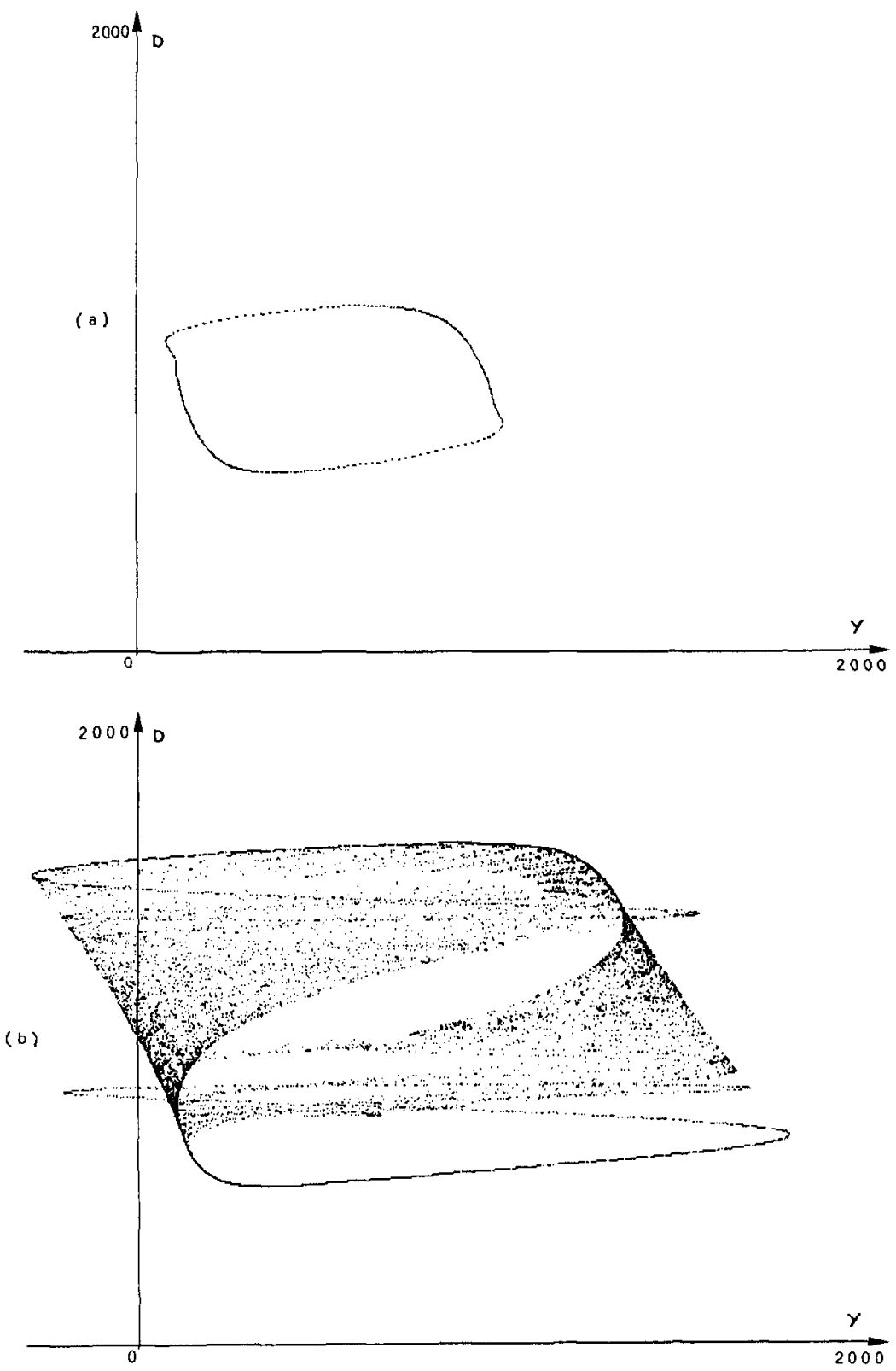

Fig. 4. Map $F$ with speculative demand $S P_{t}^{(1)}$ and $b-f_{2}(Y)$. The values of the parameters are as follows:

$a=0.07, \theta=0.5, \omega / \lambda=0.7, \beta=0.8, r=0.09, B=100, k_{1}=0.7, k_{2}=0.4, C_{0}=100, c_{1}=0.5, c_{1}^{\prime}=0.2$, $h=0.8, v^{e}=100 . b_{0}=1$ and $b_{2}=10^{-5}$ in $f_{2}(Y)$. The Hopf-bifurcation value is $b^{2 h} \simeq 0.008016$. $b_{1}=0.011$ in (a); $b_{1}=0.015$ in (b). 

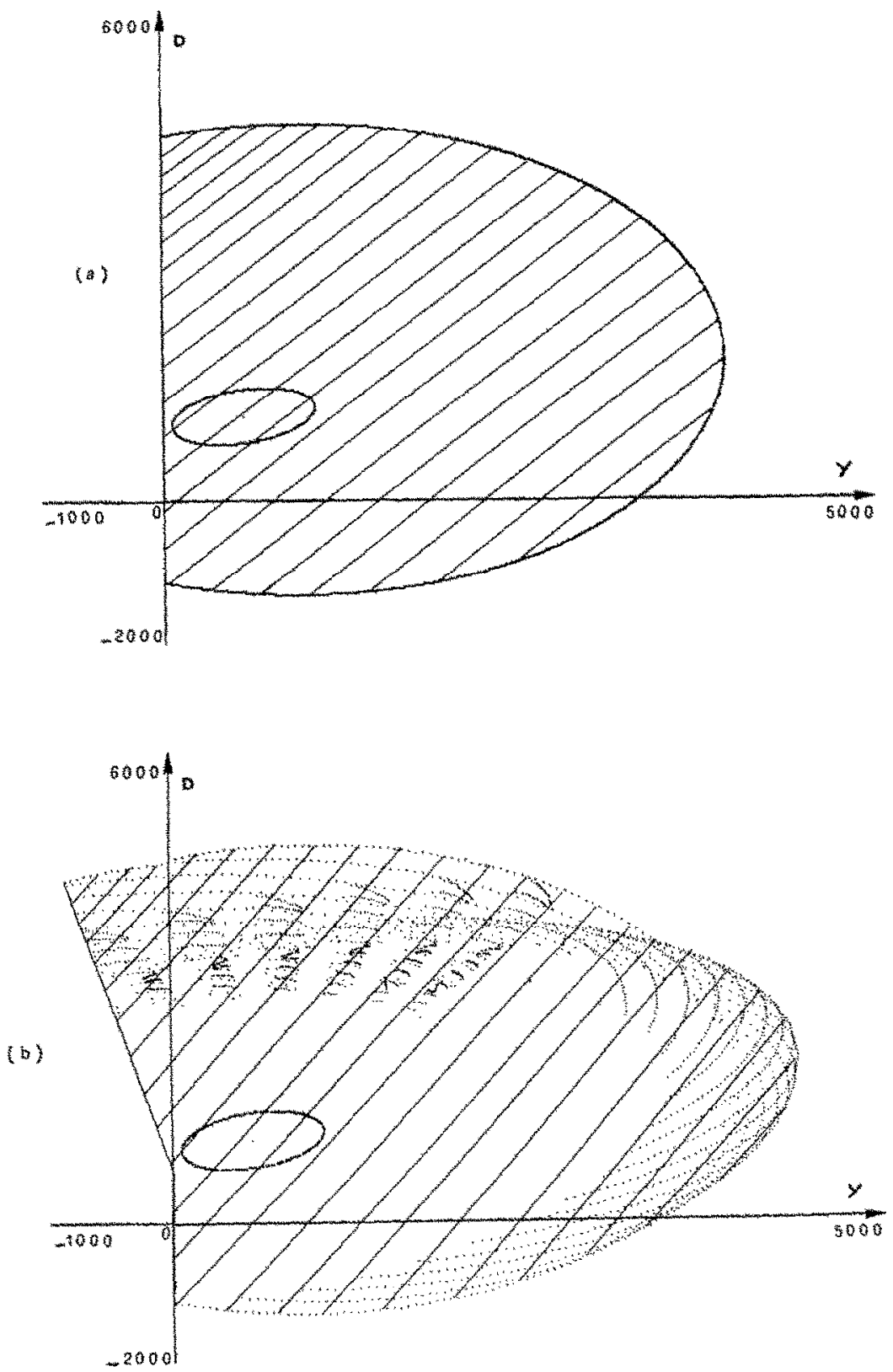

Fig. 5. Starting set $\Omega_{0}$ in (a) and invariant set $\Omega=\bigcup_{k \neq 0}^{15} \Omega_{k}$ in (b), telative to the examples given in fig. 3 . 
absorbing areas (like $\Omega$ ) making use of the "critical curves'. In noninvertible maps, absorbing areas (including stable attracting sets) may be determined, bounded by arcs of critical lines, which are also useful to characterize some global bifurcations occurring in the invariant curves $\Gamma$ or in the structure of the attracting set $\mathscr{A}$ [Gardini (1991)]. In particular, for the map $F$ with the function $b=f_{1}(Y)$, it is possible to prove that such absorbing areas, including the attracting set $\mathscr{A}$, are globally absorbing (that is to say $\mathscr{B}=\mathbb{R}^{2}$ ), whenever an attracting set $\mathscr{A}$ there exists.

\subsection{Stochastic model}

The model with rational expectations given by $S P_{t}^{(3)}$ does not have a equilibrium point or an attracting invariant curve any more, due to the presence of the stochastic variable $\varepsilon_{v}$. Let us write this stochastic map as

$$
X_{t+1}=F\left(X_{t}, \varepsilon_{t}\right),
$$

to denote that the parameter $\phi_{0}$ of the function $F\left(X_{t}\right)$ contains the variable $\varepsilon_{v}$ whose values $\varepsilon_{t}$ at each $t$ are chosen randomly in the interval $R_{v}$.

We can figure out that each point determined by (31) belongs to a particular trajectory of a deterministic map, obtained with a fixed constant value $\varepsilon$ for $\varepsilon_{v}$, say

$$
X_{t+1}=F_{\varepsilon}\left(X_{t}\right)
$$

As an example, let $X_{0}, \varepsilon_{0}$ be the starting values, then

$$
X_{1}=F\left(X_{0}, \varepsilon_{0}\right), X_{2}=F\left(X_{1}, \varepsilon_{1}\right), X_{3}=F\left(X_{2}, \varepsilon_{2}\right), \ldots
$$

is the trajectory of the stochastic map (31). On the other hand, if we consider the deterministic map $F_{\varepsilon}\left(X_{t}\right)$ as defined in (28) with $h_{i}=0$ and $\delta_{i}=\varepsilon$ a constant value at any $t$, then it is also

$$
X_{1}=F_{e_{0}}\left(X_{0}\right), X_{2}=F_{e_{1}}\left(X_{1}\right), X_{3}=F_{c_{2}}\left(X_{2}\right), \ldots
$$

Thus, the stochastic trajectory $X_{t}$ can be viewed as a sequence of points belonging to different deterministic trajectories. When each of the deterministic maps $F_{\varepsilon}\left(X_{t}\right) \varepsilon \in R_{v}$, has an attracting set $\mathscr{A}_{\varepsilon}$ (a fixed point $E_{\varepsilon}$ or an invariant curve $\Gamma_{\varepsilon}$ or a chaotic area $S_{\varepsilon}$ ), we may expect that the asymptotic state of the trajectories of the stochastic map (31) are random points which belong to a bounded region $\Omega$ of the phase-plane, containing all the attractors $\mathscr{A}_{\varepsilon}$ for each $\varepsilon \in R_{v}$. Clearly, $\Omega$ must be mapped into itself under $F\left(X_{t}, \varepsilon_{t}\right)$ or, which is the same, under $F_{\varepsilon}\left(X_{t}\right)$ for each $\varepsilon \in R_{v}$ :

\footnotetext{
${ }^{4}$ The 'critical curves' have been introduced by Gumowski and Mira (1980). These are the natural extension of the critical points (local extrema) of one-dimensional non-invertible maps, and constitute powerful tools to study global bifurcations in two-dimensional maps with a nonunique inverse, or endomorphisms (like the map $F$ discussed in this work).
} 


$$
F_{\varepsilon}(\Omega) \subseteq \Omega \text {, for each } \varepsilon \in R_{v} .
$$

We will describe a procedure for the construction of such a set $\Omega$, which is the natural extension of the procedure previously described for deterministic maps. We chose a starting set $\Omega_{0}$ such that $\mathscr{A}_{\varepsilon} \subset \Omega_{0}$ for each $\varepsilon \in R_{v}$, and consider its images for each deterministic map $F_{\varepsilon}$, let

$$
\Omega_{k}=\left\{F_{\varepsilon}\left(\Omega_{k-1}\right), \text { for each } \varepsilon \in R_{v}\right\} .
$$

In the simplest cases, there exists an integer $p$ such that

$$
\Omega=\bigcup_{k=0}^{p} \Omega_{k} \text { is mapped into itself under } F\left(X_{t}, \varepsilon_{t}\right) \text {. }
$$

Moreover, the basin of attraction of $\Omega$, say $\mathscr{B}$, can be constructed in terms of its preimages:

$$
\mathscr{B}=\bigcup_{k=0}^{\infty}\left\{F_{\varepsilon}^{-k}(\Omega), \text { for each } \varepsilon \in R_{v}\right\}
$$

Let us remark that, in general, the procedure works well when the deterministic maps $F_{\varepsilon}$ have a stable bounded attracting set $\mathscr{A}_{\varepsilon}$. In this case, even if it is not possible to define an attracting set for the stochastic map $F\left(X_{t}, \varepsilon_{t}\right)$, we have the important result that the trajectories starting in $\Omega$ will never escape from $\Omega$ (that is they are bounded), as well as trajectories starting in $\mathscr{B}$ will enter into $\Omega$, where they remain for each subsequent $t$.

We shall not give here the construction of such a set $\Omega$, but we shall give numerical evidence of its existence. As expected, the bounded stochastic trajectories are reminescent of the attractors of the different deterministic maps $F_{\varepsilon}\left(X_{t}\right)$. Some examples are illustrated.

- When conditions $(j)$ and $(j j)$ of the previous section are satisfied for each $\varepsilon \in R_{v}$, then all the deterministic maps $F_{\varepsilon}$ have an attracting fixed point $E_{\varepsilon}$, that is $\mathscr{A}_{\varepsilon}=E_{\varepsilon}$ for each $\varepsilon \in R_{v}$. In such cases we have found that the qualitative shapes of the orbits is a bounded 'cloud' of points (see fig. 6).

- When condition $(j j)$ is not satisfied for some or all the $\varepsilon$ in $R_{v}$, and $\mathscr{A}_{\varepsilon}=\Gamma_{\varepsilon}$ at these $\varepsilon, \mathscr{A}_{\varepsilon}=E_{\varepsilon}$ for the other $\varepsilon$, the qualitative shape of the orbits is a 'band-structure', reminescent of the $\Gamma_{\varepsilon}$-curves (see fig. 7a).

- When $\mathscr{A}_{\varepsilon}=S_{c}$ for some or all the $\varepsilon$ in $R_{v}, \mathscr{A}_{s}=\Gamma_{\varepsilon}$ or $\mathscr{A}_{\varepsilon}=E_{\varepsilon}$ at the other $\varepsilon$, a stochastic-chaotic area is observed which is qualitatively similar to that of the deterministic maps (see fig. $7 b$ ).

Clearly, the widths of the 'clouds' or of the 'bands' depend on the magnitude of the range $R_{v}$, they increase on increasing $R_{v}$. 

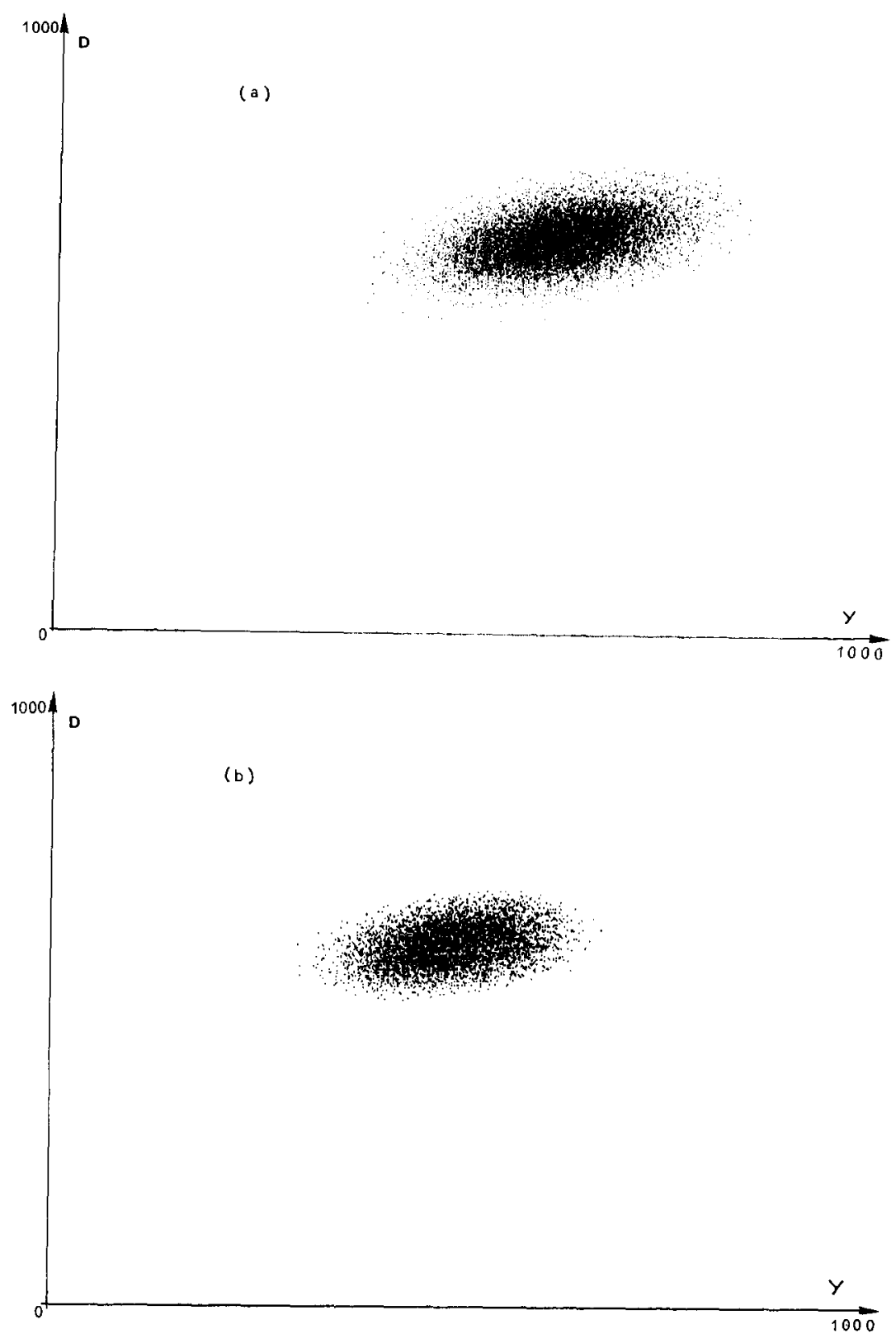

Fig. 6. Stochastic map $F$ with $\varepsilon \in R_{v}=[-200,200]$.

In (a): $a=0.1, \theta=0.5, \omega / \lambda=0.7, \beta=0.8, r=0.14, B=100, k_{1}=0.7, k_{2}=0.4, C_{0}=100, c_{1}=0.5$, In (b): $a=0.07, \theta=0.5, \omega / \lambda=0.7, \beta=0.8, r=0.12, B=100, k_{1}=0.8, k_{2}=0.5, C_{0}=100, c_{1}=0.5$, $c_{1}^{\prime}=0.2 . b=f_{2}(Y)$ with $b_{0}=1, b_{1}=0.009$ and $b_{2}=10^{-5}$. 
D. Deli Gatt et al, Investment confidence

185

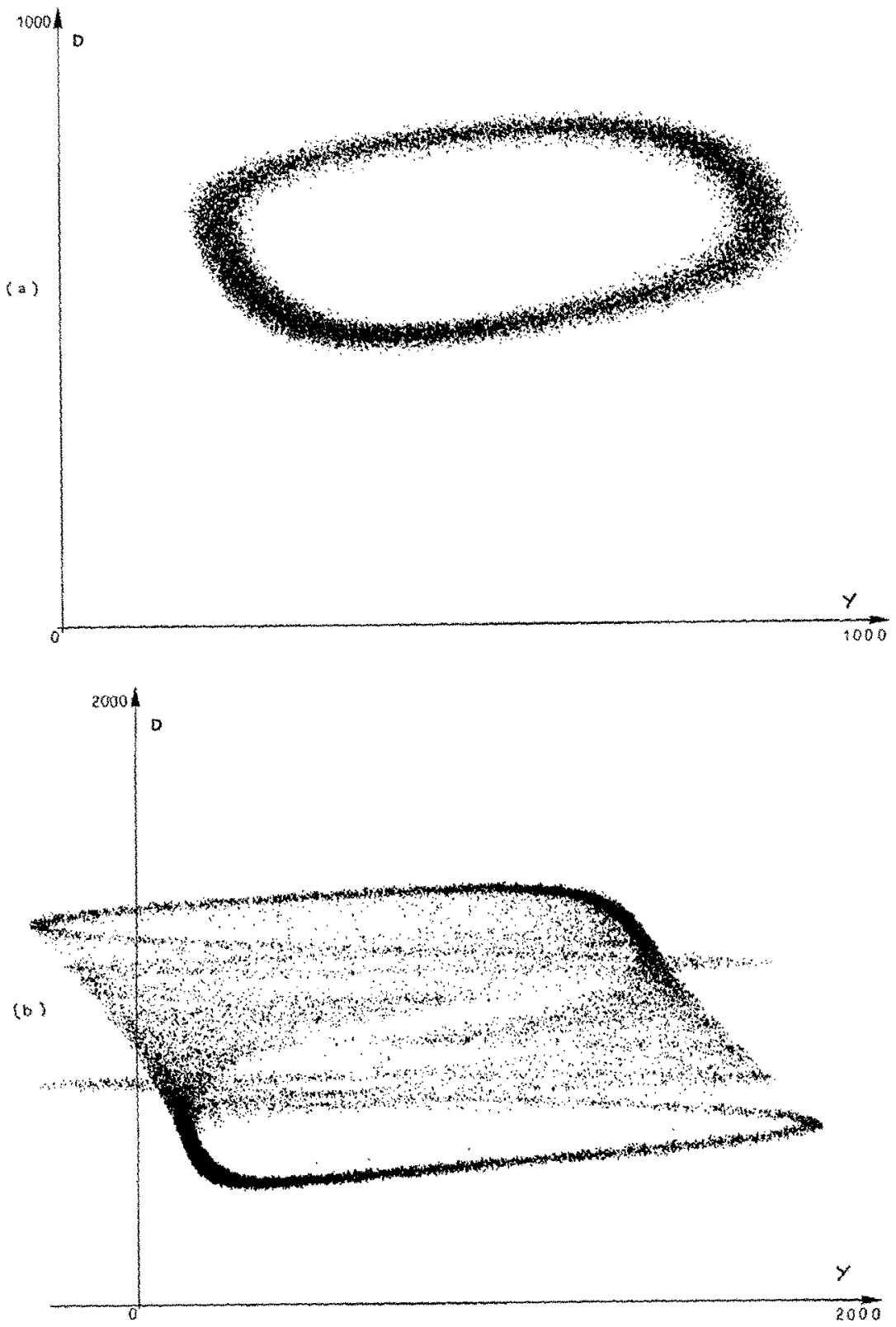

Fig. 7. Stochastic map $F$ with $\varepsilon \in R_{y}=[-100,100]$.

Except for $b_{1}$, the values of the parameters are as in $6 \mathrm{gg}$. $6 \mathrm{~b}, b_{1}=0.011$ in (a); $b_{1}=0.0165$ in (b). 


\section{Conclusions}

In this paper we have presented a macrodynamic model whose main behavioral equations are grounded in the New Keynesian literature. By assuming asymmetric information on capital markets we can reject the Modigliani-Miller irrelevance proposition and devise a 'pecking order' of financing sources in which internally generated cash flow ranks first. Investment expenditure is linked to internal finance through a crucial nonlinear parameter (the propensity to invest) which we assume to be procyclical. The interaction between retained profits and debt commitments is the ultimate source of endogenously determined investment and income fluctuations. Therefore the model provides a theoretical rationale for the mechanism of the business cycle in the postwar era envisaged by Eckstein and Sinai (1986). According to the value of the propensity to invest, the dynamic paths of income and corporate debt can converge to long-run steady-state values, exhibit chaotic properties or lead to 'financial crises'. Additive stochastic disturbances do not alter the fundamental properties of the dynamics, but can be held responsible for the switch from a dynamic regime to another one, if they modify the parameters in a critical region.

\section{References}

Abel, A. and O. Blanchard, 1986, The present value of profits and cyclical movement in investment, Econometrica 54, 249-273.

Akerlof, G. and J. Yellen, 1985, A near rational model of the business cycle, with wage and price inertia, Quarterly Journal of Economics 100, 823-838.

Ball, L., G. Mankiw and D. Romer, 1988, The New Keynesian economics and the outputinflation trade off, Brooking Papers on Economic Activity 1, 1-65.

Barugola, A., J.C. Cathala and C. Mira, 1986, Annular chaotic areas, Nonlinear Analysis T.M. and $\Lambda .10,1223-1236$.

Bernanke, B. and M. Gertler, 1989, Agency costs, new worth and business fluctuations, American Economic Review 79, 14-31.

Bernanke, B. and M. Gertler, 1990, Financial fragility and economic performance, Quarterly Journal of Economics 105, 87-114.

Blanchard, O., 1990, Why does money affect output? in: B. Friedman and F. Hann, eds., Handbook of monetary economics (North Holland, Amsterdam).

Calomiris, C. and G. Hubbard, 1988, Firm heterogeneity, internal finance and credit rationing, NBER Working Paper no. 2497.

Day, R., 1989, Comparative monetary and fiscal policy dynamics, in: W. Semmler, ed., Financial dynamics and business cycles: New perspectives (Sharpe, Armonk).

Day, R. and W. Shafer, 1985, Keynesian chaos, Journal of Macroeconomics 7, 277-295.

Day, R. and W. Shafer, 1987, Ergodic fluctuations in deterministic economic models, Journal of Economic Behavior and Organization 8, 339-361.

Day, R. and T. Lin, 1991, A Keynesian business cycle, in: E.J. Nell and W. Semmler, eds., Nicholas Kaldor and mainstream economics (Macmillan, New York).

Eckstein, O. and A. Sinai, 1986, The mechanism of the business cycle in the post war era, in R. Gordon, ed., The American business cycle (Chicago University Press, Chicago).

Fazzari, S., G. Hubbard and B. Petersen, 1988, Financing constraints and corporate investment, Brookings Papers on Economic Activity 1, 141-195.

Gabisch, G. and H.W. Lorenz, 1989, Business cycle theory (Springer, New York). 
Gallegati, M. and L. Gardini, 1991, A nonliear model of the business cycle with money and finance, Metroeconomica 42, 1-36.

Gandolfo, G., 1983, Economic dynamics: Methods and models (North-Holland, Amsterdam).

Gardini, L., 1991, On the global bifurcations of invariant curves and global analysis of twodimensional endomorphisms, Mimeo.

Gertler, M. and G. Hubbard, 1988, Financial factors in business fluctuations, NBER working paper no. 2758.

Goldfeld, S.M., 1976, The case of the missing money, Brookings Papers on Economic Activity 3, 683-730.

Gordon, R., 1990, What is new Keynesian economics?, Journal of Economic Literature 28 , $1115-1171$.

Greenwald, B., J. Stiglitz and A. Weiss, 1984, Information imperfections in the capital market and macroeconomic fluctuations, American Economic Review 74, 194-199.

Guckenheimer, J. and P.H. Holmes, 1983, Nonlinear oscillations, dynamical systems and bifurcation of vector fields (Springer-Verlag, New York).

Gumowski, I. and C. Mira, 1980, Dinamique caotique (Cepadues, Toulouse).

Hamburger, M., 1977, Behaviour of the money stock: Is there a puzzle?, Journal of Monetary Economics 3, 25-40.

Hendry, D.F., 1983, Econometric modelling: The 'consumption function' in retrospect, Scottish Journal of Political Economy 30, 193-220.

Hubbard, G. and A. Kashyap, 1990, Internal net worth and the investment process: An application to U.S. agriculture, NBER working paper no. 3339.

Iooss, G., 1979, Bifurcation of maps and applications (North Holland, Amsterdam).

Keynes, J.M., 1936, The general theory of employment, interest and money, (Macmillan, London).

King, R. and C. Plosser, 1984, Money, credit and prices in a real business cycle, American Economic Review 74, 363-380.

King, S., 1983, Macroeconomic activity and the rate of interest, Mimeo. (North-Western University).

Long, J.B. and C. Plosser, 1983, Real business cycle, Journal of Political Economy 91, 39-69.

Lorenz, H.W., 1989, Nonlinear dynamical economic and chaotic motion (Springer-Verlag, New York).

Mankiw, G., 1985, Small menu costs and large business cycles: A macroeconomic model of monopoly, Quarterly Journal of Economics 100, 529-538.

Mankiw, G. and D. Romer, eds., 1991, The new Keynesian economics (MIT Press, Cambridge).

Marotto, J.R., 1978, Snap-back repellers imply chaos in $R^{n}$, Nonlinear Analysis T.M. and Applications 63, 199-223.

Minsky, H., 1986, Stabilizing an unstable economy (Yale University Press, New Haven).

Mira, C., 1987, Chaotic dynamics (World Scientific, Singapore).

Myers, S. and E. Majluf, 1984, Corporate financing and investment decisions when firms have information that investors do not have, Journal of Financial Economics 13, 187-221.

Rotemberg, J., 1987, The new-Keynesian microfoundation, NBER Macroeconomics Annual 2, 69-104.

Stiglitz, J., 1987, The causes and consequences of the dependence of quality on prices, Journal of Economic Literature 25, 1-48.

Stiglitz, J. and A. Weiss, 1981, Credit rationing in market with imperfect information, American Economic Review 71, 393-410.

Tobin, J., 1970, Post hoc ergo propter hoc, Quarterly Journal of Economics 84, 310-317. 